\title{
In vitro inhibition of human cytochrome P450 enzymes by the novel atypical antipsychotic drug asenapine: a prediction of possible drug-drug interactions
}

\author{
Jacek Wójcikowski ${ }^{1} \cdot$ Przemysław J. Danek $^{1} \cdot$ Agnieszka Basińska-Ziobroń $^{1} \cdot$ Renata Pukło $^{1} \cdot$ Władysława A. Daniel $^{1}$
}

Received: 19 November 2019 / Revised: 20 February 2020 / Accepted: 26 February 2020 / Published online: 26 March 2020

(c) The Author(s) 2020

\begin{abstract}
Background Inhibition of cytochrome P450 (CYP) enzymes is the most common cause of harmful drug-drug interactions. The present study aimed at examining the inhibitory effect of the novel antipsychotic drug asenapine on the main CYP enzymes in human liver.

Methods The experiments were performed in vitro using pooled human liver microsomes and the human cDNA-expressed CYP enzymes: CYP1A2, CYP2C9, CYP2C19, CYP2D6, and CYP3A4 (Supersomes). Activities of CYP enzymes were determined using the CYP-specific reactions: caffeine 3- $N$-demethylation (CYP1A2), diclofenac 4'-hydroxylation (CYP2C9), perazine $N$-demethylation (CYP2C19), bufuralol 1'-hydroxylation (CYP2D6), and testosterone 6 $\beta$-hydroxylation (CYP3A4). The rates of the CYP-specific reactions were assessed in the absence and presence of asenapine using HPLC.

Results The obtained results showed that both in human liver microsomes and Supersomes asenapine potently and to a similar degree inhibited the activity of CYP1A2 via a mixed mechanism $\left(K_{i}=3.2 \mu \mathrm{M}\right.$ in liver microsomes and Supersomes $)$ and CYP2D6 via a competitive mechanism ( $K_{i}=1.75$ and $1.89 \mu \mathrm{M}$ in microsomes and Supersomes, respectively). Moreover, asenapine attenuated the CYP3A4 activity via a non-competitive mechanism $\left(K_{i}=31.3\right.$ and $27.3 \mu \mathrm{M}$ in microsomes and Supersomes, respectively). In contrast, asenapine did not affect the activity of CYP2C9 or CYP2C19.

Conclusion The potent inhibition of CYP1A2 and CYP2D6 by asenapine, demonstrated in vitro, will most probably be observed also in vivo, since the calculated $K_{i}$ values are close to the presumed concentration range for asenapine in the liver in vivo. Therefore, pharmacokinetic interactions involving asenapine and CYP2D6 or CYP1A2 substrates are likely to occur during their co-administration to patients.
\end{abstract}

Keywords Asenapine · Cytochrome P450 · Inhibition · Human liver microsomes · cDNA-expressed CYP enzymes

\section{Abbreviations}

CYP Cytochrome P450

HPLC High-performance liquid chromatography

SSRIs Selective serotonin reuptake inhibitors

Jacek Wójcikowski: Deceased.

Władysława A. Daniel

nfdaniel@cyf-kr.edu.pl

1 Department of Pharmacokinetics and Drug Metabolism, Maj Institute of Pharmacology, Polish Academy of Sciences, Smętna 12, 31-343 Kraków, Poland

\section{Introduction}

Cytochrome P450 (CYP) enzymes are members of a superfamily of heme-containing monooxygenases catalyzing the metabolism of endogenous substances (e.g., steroids, monoaminergic neurotransmitters, and arachidonic acid) and the majority of clinically important drugs, including psychotropics. CYP1A2, CYP2C9, CYP2C19, CYP2D6, and CYP3A4, constitute $13,20-30,4,1.5$, and $30-50 \%$ of the total CYP protein in human liver, respectively, and are involved in the metabolism of approximately $90 \%$ of all marketed drugs [1-4]. They are pivotal CYP isoforms in the evaluation of CYP-mediated drug-drug interactions.

The catalytic activity of cytochromes P450 includes most often C-oxidation reactions (hydroxylation, epoxidation, and peroxidation), $\mathrm{N}$ - and $\mathrm{S}$-oxidation, as well as oxidative O-, S-, or N-dealkylation, and other types of reactions. 
These reactions are engaged in the first phase of xenobiotic (drug) metabolism and in the biosynthesis and metabolism of endogenous compounds. The primary goal of the firstphase metabolism of xenobiotics by cytochrome $\mathrm{P} 450$ is their biotransformation into an inactive form with increased solubility in water to facilitate the deactivation and excretion of xenobiotics from the body [5]. However, metabolism may sometimes result in the formation of active metabolites that have pharmacological activities similar to those of the parent compound or with entirely different biological properties, including the ability to alter the metabolism of other chemical compounds. That situation applies to many chemical carcinogens, while the increased biological activity is desirable for pro-drugs [6].

Asenapine is a new atypical antipsychotic drug that has been developed as a structural modification of the antidepressant drug mianserin. Chemically, asenapine is categorized within the family of dibenzoxepinopyrrolidines [7]. The drug is currently approved for the acute and maintenance treatment of schizophrenia as well as for acute treatment of manic or mixed episodes associated with bipolar I disorder with or without psychotic features as monotherapy or adjunctive medication along with lithium or valproate. Asenapine has a unique human receptor-binding profile characterized by an antagonistic action at serotonergic $\left(5-\mathrm{HT}_{2}, 5-\mathrm{HT}_{5-7}\right)$, adrenergic $\left(\alpha_{1}\right.$ and $\left.\alpha_{2}\right)$, dopaminergic $\left(D_{1-4}\right)$, and histaminergic $\mathrm{H}_{1}$ receptors, but produces no action on the $\beta$-adrenergic or muscarinic receptors $[8,9]$. Due to its pharmacological profile, asenapine is effective not only against positive (psychotic) symptoms by affecting dopaminergic receptors, but it is also efficient against negative symptoms of schizophrenia improving mood and cognition (via 5- $\mathrm{HT}_{1 \mathrm{~A}}, \mathrm{HT}_{2 \mathrm{C}}, 5-\mathrm{HT}_{6}$, and 5- $\mathrm{HT}_{7}$ ), and simultaneously protecting against extrapyramidal symptoms (via $5-\mathrm{HT}_{2 \mathrm{~A}}$ ) $[9,10]$. Asenapine is metabolized to 38 different metabolites, none of which has any significant functional activity at receptors. Asenapine appears to be metabolized via four primary metabolic pathways to $N$-desmethylasenapine, 11-hydroxy-asenapine, asenapine $\mathrm{N}$-oxide, and asenapine $\mathrm{N}$-glucuronide. With the exception of the glucuronide, the primary metabolites are all further extensively metabolized. The primary mechanism of asenapine metabolism involves glucuronidation through UDP glucuronosyltransferase 1A4 (UGT1A4), producing asenapine- $N$-glucuronide. The other major metabolite of asenapine is produced through demethylation, resulting in $N$-desmethylasenapine, primarily via CYP1A2, with only minor contributions of CYP3A4 and CYP2D6. The estimated terminal half-life $\left(t_{1 / 2}\right)$ in adults is approximately $24 \mathrm{~h}$. Asenapine is rapidly distributed, has a large volume of distribution, and is highly bound to plasma proteins $(95 \%)$. Elimination of asenapine and its metabolites occurs approximately equally via hepatic and renal routes $[7,11,12]$.

Direct inhibition of CYP enzymes is the most common cause of harmful drug-drug interactions. Inhibition of drug metabolism can lead to a decreased elimination and increased bioavailability (a decreased first-pass effect) of the parent compound. If a drug is metabolized mainly via a single metabolic pathway, its inhibition may result in an increased steady-state concentration and accumulation ratio, and non-linear kinetics as a consequence of enzyme saturation. In the case of pro-drugs, enzyme inhibition may result in a decrease in the amount of the active drug form $[4,13]$.

Previous in vitro metabolic studies have shown that typical neuroleptics (phenothiazines) are potent inhibitors of human CYP2D6 (thioridazine, chlorpromazine, levomepromazine, and perhenazine) and CYP1A2 (perazine), as well as week inhibitors of CYP1A2, CYP2C9, CYP2C19, or CYP3A4. In comparison, the older atypical antipsychotics, like clozapine, olanzapine, risperidone, and zipasidone, moderately diminish the activity of CYP2D6, and weakly inhibit that of CYP3A4, CY2C9, and CYP2C19 in human liver [14-19].

Although there are some experimental data showing a possibility of inhibition of CYP isoforms by typical and older atypical neuroleptics, the inhibition studies of human CYP enzymes by the novel antipsychotic drug asenapine have not been presented, so far. Therefore, this work aimed at examining the inhibitory effect of asenapine on the main human liver CYP enzymes: CYP1A2, CYP2C9, CYP2C19, CYP2D6, and CYP3A4.

\section{Materials and methods}

\section{Drugs and chemicals}

Asenapine, caffeine, 3- $N$-desmethyl caffeine (paraxanthine), diclofenac, 4'-hydroxydiclofenac, bufuralol, 1'-hydroxybufuralol, NADP, NADPH, glucose-6-phosphate, glucose6-phosphate-dehydrogenase, $\mathrm{MgCl}_{2}, \mathrm{KCl}, \mathrm{ZnSO}_{4}$, Trizma base, and ethylenediaminetetraacetic acid (EDTA) were purchased from Sigma (St. Louis, USA). Testosterone and $6 \beta$-testosterone were from Steraloids (Newport, USA). All the organic solvents with HPLC purity were supplied by Merck (Darmstadt, Germany). Pooled human liver microsomes and microsomes from baculovirus-infected insect cells expressing human CYP1A2, CYP2C9, CYP2C19, CYP2D6, and CYP3A4 (Supersomes) were provided by Corning (Woburn, USA). 


\section{Determination of CYP enzyme activities}

\section{CYP1A2 activity assay}

The activity of CYP1A2 was investigated by measuring the rate of a CYP1A2-specific reaction, i.e., 3- $N$-demethylation of caffeine, as described previously [20]. Briefly, incubations were carried out in a system containing pooled human liver microsomes (ca. $0.5 \mathrm{mg}$ of protein $/ \mathrm{ml}$ ), a phosphate buffer $(0.15 \mathrm{M}, \mathrm{pH} 7.4)$, and NADPH $(1 \mathrm{mM})$. The rate of caffeine 3 - $N$-demethylation was assessed at the substrate concentrations of 200,400 , and $800 \mu \mathrm{M}$, in the absence and presence of asenapine, added in vitro (asenapine concentrations: 0.01 , $0.05,0.1,0.5,1,5$, and $10 \mu \mathrm{M})$. The final incubation volume was $0.5 \mathrm{ml}$. After a 50 -min incubation, the reaction was terminated by adding $700 \mu \mathrm{l}$ of a $2 \% \mathrm{ZnSO}_{4}$ and $50 \mu \mathrm{l}$ of $2 \mathrm{M} \mathrm{HCl}$. In the case of microsomes from baculovirusinfected insect cells expressing CYP1A2 (Supersomes 1A2), the effect of asenapine on the CYP1A2 activity was studied under experimental conditions similar to those described for human liver microsomes, except for the fact that the final concentration of CYP1A2 was $50 \mathrm{pmol} / \mathrm{ml}$ and the incubation time was $30 \mathrm{~min}$. Concentrations of caffeine and its metabolite 3- $N$-desmethyl caffeine (paraxanthine), produced in liver microsomes or Supersomes 1A2, were assessed using the HPLC method with UV detection, as described previously [20].

\section{CY2C9 activity assay}

The activity of CYP2C9 was examined by measuring the rate of a CYP2C9-specific reaction, i.e., 4'-hydroxylation of diclofenac, as described previously [19]. Briefly, incubations were carried out in a system containing pooled human liver microsomes (ca. $0.5 \mathrm{mg}$ of protein $/ \mathrm{ml}$ ), a Tris/ $\mathrm{KCl}$ buffer $(50 \mathrm{mM}, \mathrm{pH}=7.4), \mathrm{MgCl}_{2}(3.0 \mathrm{mM})$, EDTA $(1 \mathrm{mM})$, NADP $(1.0 \mathrm{mM})$, glucose 6 -phosphate $(5 \mathrm{mM})$, and glucose-6-phosphate-dehydrogenase $(1.7 \mathrm{U}$ in $1 \mathrm{ml})$. The rate of diclofenac 4'-hydroxylation was assessed at the substrate concentrations of 5,10 , and $25 \mu \mathrm{M}$, in the absence and presence of asenapine, added in vitro (asenapine concentrations: $0.01,0.05,0.1,0.5,1,5$, and $10 \mu \mathrm{M})$. The final incubation volume was $0.5 \mathrm{ml}$. After a 30 -min incubation, the reaction was stopped by adding $100 \mu \mathrm{l}$ of acetonitrile. The effect of asenapine on the CYP2C9 activity in microsomes from baculovirus-infected insect cells expressing CYP2C9 (Supersomes 2C9) was studied under experimental conditions similar to those described for human liver microsomes. The final concentration of CYP2C 9 was $50 \mathrm{pmol} / \mathrm{ml}$. Concentrations of diclofenac and its metabolite 4'-hydroxydiclofenac, formed in liver microsomes or Supersomes 2C9, were assessed by the HPLC method with UV detection, as described previously [21].

\section{CY2C19 activity assay}

The activity of CYP2C19 was estimated by measuring the rate of a CYP2C19-specific reaction, i.e., $N$-demethylation of perazine, as described previously [22]. Briefly, incubations were carried out in a system containing pooled human liver microsomes (ca. $0.5 \mathrm{mg}$ of protein/ml), a Tris/ $\mathrm{KCl}$ buffer $(50 \mathrm{mM}, \mathrm{pH}=7.4), \mathrm{MgCl}_{2}(3.0 \mathrm{mM})$, EDTA $(1 \mathrm{mM})$, NADP $(1.0 \mathrm{mM})$, glucose 6 -phosphate $(5 \mathrm{mM})$, and glucose-6-phosphate-dehydrogenase $(1.7 \mathrm{U}$ in $1 \mathrm{ml})$. The rate of perazine $N$-demethylation was measured at the substrate concentrations of 50,100 , and $200 \mu \mathrm{M}$, in the absence and presence of asenapine, added in vitro (asenapine concentrations: $0.01,0.05,0.1,0.5,1,5$, and $10 \mu \mathrm{M}$ ). The final incubation volume was $0.5 \mathrm{ml}$. After a $20-\mathrm{min}$ incubation (liver microsomes), the reaction was stopped by adding $100 \mu \mathrm{l}$ of methanol. The effect of asenapine on the CYP2C19 activity in microsomes from baculovirus-infected insect cells expressing CYP2C19 (Supersomes 2C19) was studied under experimental conditions similar to those described for human liver microsomes. The final concentration of CYP2C19 was $50 \mathrm{pmol} / \mathrm{ml}$ and the incubation time was $30 \mathrm{~min}$. Concentrations of perazine and its metabolite $\mathrm{N}$-desmethylperazine, produced in liver microsomes or Supersomes 2C19, were assessed by the HPLC method with UV detection, as described previously [22].

\section{CY2D6 activity assay}

The activity of CYP2D6 was evaluated on the basis of the rate of a CYP2D6-specific reaction, i.e., 1'-hydroxylation of bufuralol, as described previously [23]. Briefly, incubations were carried out in a system containing pooled human liver microsomes (ca. $0.5 \mathrm{mg}$ of protein $/ \mathrm{ml}$ ), a potassium phosphate buffer $(0.1 \mathrm{M}, \mathrm{pH}=7.4), \mathrm{MgCl}_{2}(3.3 \mathrm{mM})$, NADP (1.3 mM), glucose 6-phosphate $(3.3 \mathrm{mM})$, and glucose-6-phosphate-dehydrogenase $(1.0 \mathrm{U}$ in $1 \mathrm{ml})$. The rate of bufuralol 1'-hydroxylation was assessed at the substrate concentrations of 10,25 , and $50 \mu \mathrm{M}$, in the absence and presence of asenapine, added in vitro (neuroleptic concentrations: $0.01,0.05,0.1,0.5,1,5$, and $10 \mu \mathrm{M})$. The final incubation volume was $0.5 \mathrm{ml}$. After a 30-min incubation, the reaction was stopped by adding $30 \mu \mathrm{l}$ of a $70 \%$ perchloric acid. The effect of asenapine on the CYP2D6 activity in microsomes from baculovirus-infected insect cells expressing CYP2D6 (Supersomes 2D6) was studied under experimental conditions similar to those described for human liver microsomes. The final concentration of CYP2D6 was 
$50 \mathrm{pmol} / \mathrm{ml}$. Concentrations of bufuralol and its metabolite 4'-hydroxybufuralol in liver microsomes or Supersomes 2D6 were assessed by the HPLC method with fluorimetric detection, as described previously [23].

\section{CY3A4 activity assay}

The activity of CYP3A4 was studied by measuring the rate of $6 \beta$-hydroxylation of testosterone, a CYP3A4-specific reaction, as described previously [24]. Briefly, incubation was carried out in a system containing pooled human liver microsomes (ca. $0.5 \mathrm{mg}$ of protein $/ \mathrm{ml}$ ), a Tris $/ \mathrm{KCl}$ buffer (50 mM, pH =7.4), $\mathrm{MgCl}_{2}(3.0 \mathrm{mM})$, EDTA $(1 \mathrm{mM})$, NADP (1.0 mM), glucose 6-phosphate $(5 \mathrm{mM})$, and glucose-6-phosphate-dehydrogenase $(1.7 \mathrm{U}$ in $1 \mathrm{ml})$. The rate of testosterone $6 \beta$-hydroxylation was assessed at the substrate concentrations of 50,100 , and $200 \mu \mathrm{M}$, in the absence and presence of asenapine, added in vitro (asenapine concentrations: $0.01,0.05,0.1,0.5,1,5$, and $10 \mu \mathrm{M})$. The final incubation volume was $0.5 \mathrm{ml}$. After a 20 -min incubation, the reaction was stopped by adding $200 \mu \mathrm{l}$ of methanol. The effect of asenapine on the CYP3A4 activity in microsomes from baculovirus-infected insect cells expressing CYP3A4 (Supersomes 3A4) was studied under experimental conditions similar to those described for human liver microsomes. The final concentration of CYP3A4 was $50 \mathrm{pmol} / \mathrm{ml}$ and the incubation time was $30 \mathrm{~min}$. Concentrations of testosterone and its metabolite $6 \beta$-hydroxytestosterone, formed in liver microsomes or Supersomes 3A4, were assessed by the HPLC method with UV detection, as described previously [24].

\section{Determination of kinetic parameters, $K_{i}$ and $\mathrm{IC}_{50}$ values, and the mechanism of inhibition}

Kinetic parameters $\left(K_{m}, V_{\max }, K_{i}\right)$ describing the metabolism of CYP-specific substrates in liver microsomes and Supersomes were obtained using the Michaelis-Menten approach and a non-linear regression analysis (Program Sigma Plot 12.3 Enzyme Kinetics). The inhibitory effects of asenapine on CYP enzymes are presented graphically as Dixon's plots (1/V against I) indicating $K_{i}$ values, and Lineweaver-Burk's plots $(1 / \mathrm{V}$ against $1 / \mathrm{S})$ showing the mechanism of inhibition (competitive inhibition increases the $K_{m}$ value, not affecting the $V_{\max }$ value; non-competitive inhibition decreases the $V_{\max }$ value, not affecting the $K_{m}$ value; mixed inhibition entails respective changes in both the $K_{m}$ and $V_{\max }$ values).

The $\mathrm{IC}_{50}$ values (asenapine concentrations required for $50 \%$ inhibition of particular CYP enzymes in vitro) were determined by plotting relative CYP activities vs. the logarithm of asenapine concentrations, using GraphPad Prism 7.0 (GraphPad Prism Software Inc., CA, USA).

\section{Results}

Dixon's plots of the metabolism of CYP-specific substrates, carried out in human liver microsomes and Supersomes CYP1A2, CYP2D6, and CYP3A4, in the absence or presence of asenapine, demonstrated that the examined neuroleptic exerted a significant inhibitory effect on CYP1A2, CYP2D6, and CYP3A4; however, its potency in relation to specific CYP isoenzymes was diverse (main plots in Figs. 1a, b; 2a, b; 3a, b). Both in human liver microsomes and Supersomes asenapine potently and, to a similar degree, inhibited the activity of CYP1A2 $\left(K_{i}=3.2 \mu \mathrm{M}\right.$ in liver microsomes and Supersomes) and CYP2D6 ( $K_{i}=1.75$ and $1.89 \mu \mathrm{M}$ in liver microsomes and Supersomes, respectively). Moreover, asenapine attenuated the CYP3A4 activity $\left(K_{i}=31.3\right.$ and $27.3 \mu \mathrm{M}$ in liver microsomes and Supersomes, respectively).

Lineweaver-Burk's plots indicated that both in human liver microsomes and Supersomes asenapine inhibited the activity of CYP1A2 via a mixed mechanism, CYP2D6 via a competitive mechanism, and that of CYP3A4 via a noncompetitive mechanism (inserts in Figs. 1a, b; 2a, b; 3a, b). The $K_{i}$ values and mechanisms of inhibition of CYP1A2, CYP2D6, and CYP3A4 activities by asenapine are summarized in Table 1.

In addition, the $\mathrm{IC}_{50}$ values obtained for the asenapine inhibition of cytochrome $\mathrm{P} 450$ enzyme activities in vitro in human liver microsomes and human cDNA-expressed CYP enzymes (Supersomes) are shown in Table 2. The obtained $\mathrm{IC}_{50}$ values confirmed the ability of asenapine to inhibit the CYP1A2, CYP2D6, and CYP3A4 activities.

On the other hand, asenapine did not affect the activity of CYP2C9 or CYP2C19, neither in liver microsomes, nor in Supersomes (Fig. 4).

\section{Discussion}

When cytochrome $\mathrm{P} 450$ is inhibited, the pharmacokinetics of a drug which is metabolized by this enzyme will change, thereby increasing the drug efficacy or causing drug toxicity. As mentioned in the introduction, asenapine is mainly metabolized by CYP1A2, with a small contribution of CYP3A4 and CYP2D6 [7, 11, 12]. Therefore, the use of strong inhibitors of these enzymes may cause drug-drug interactions. Furafylline, quinidine, and ketaconazole are potent inhibitors of CYP enzymes (1A2, 2D6, and 3A4, 


\section{A Liver microsomes}

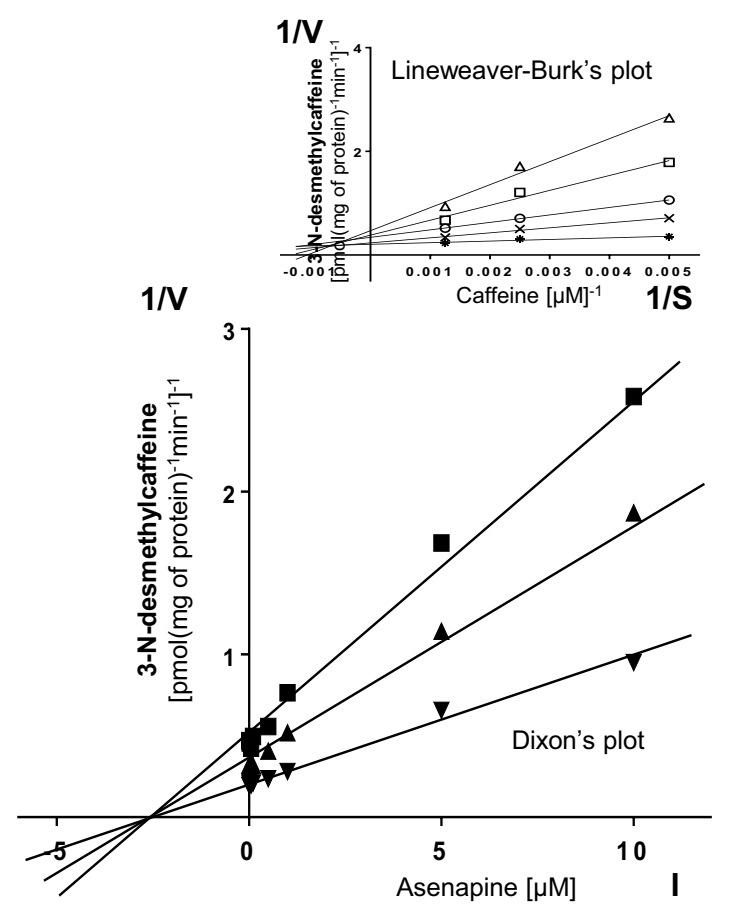

Fig. 1 The influence of asenapine on the activity of CYP1A2 measured as a rate of caffeine 3- $N$-demethylation. a Human liver microsomes $\left(K_{m}=709 \mu \mathrm{M}, V_{\max }=9.67 \mathrm{pmol} / \mathrm{mg}\right.$ protein $\left./ \mathrm{min}\right)$. b Human cDNA-expressed CYP1A2 (Supersomes CYP1A2) $\left(K_{m}=705 \mu \mathrm{M}\right.$, $\left.V_{\max }=1.92 \mathrm{pmol} / \mathrm{pmol} \mathrm{CYP} / \mathrm{min}\right)$. Each point represents the mean value of two independent analyses. $V$ velocity of the reaction, $I$ the

respectively). When these inhibitors are co-administered with asenapine, the metabolism of the neuroleptic may be inhibited. Then, the plasma concentration of asenapine may increase, and adverse drug-drug interaction might occur. Asenapine is not metabolized by CYP2C9 or CYP2C19. Therefore, the combination of asenapine with selective inhibitors for these enzymes (e.g., sulfaphenazole for CYP2C9 or (-)- $N$-3-benzyl-phenobarbital for CYP2C19) will not affect the metabolism of asenapine.

Another question that arises in drug development is whether a new drug may inhibit the metabolism of other concurrently administered drugs. One approach to answer this question is to examine whether the new drug may inhibit the metabolism of known specific substrates of cytochrome P450 enzymes in vitro. The obtained results demonstrated that asenapine exerted significant inhibitory effects on CYP1A2, CYP2D6, and CYP3A4 activities measured as the rates of caffeine 3- $N$-demethylation, bufuralol 1'-hydroxylation, and testosterone $6 \beta$-hydroxylation, respectively. However, its potency in

\section{B Supersomes 1A2}

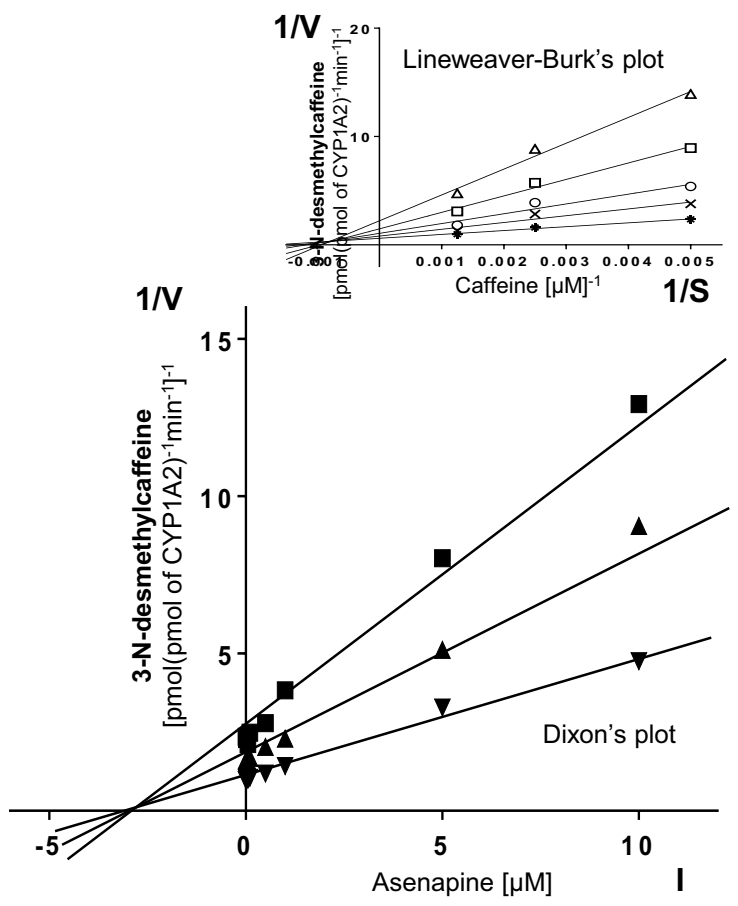

concentration of the inhibitor (asenapine), $S$ the concentration of the substrate (caffeine). The $K_{i}$ values and mechanisms of inhibition are shown in Table 1. Dixon's plots (the main plots): the caffeine concentration of $200 \mu \mathrm{M}(\boldsymbol{\square}), 400 \mu \mathrm{M}(\boldsymbol{\Delta})$, and $800 \mu \mathrm{M}(\boldsymbol{\nabla})$. LineweaverBurk's plots (inserts): control-no asenapine (*); the asenapine concentration of $0.5 \mu \mathrm{M}(\mathbf{x}), 1 \mu \mathrm{M}(\bigcirc), 5 \mu \mathrm{M}(\square)$, and $10 \mu \mathrm{M}(\triangle)$

affecting specific CYP enzymes was diverse. Asenapine potently inhibited CYP1A2 and CYP2D6 via a mixed or competitive mechanism (respectively), and weakly diminished the activity of CYP3A4 via a non-competitive mechanism. On the other hand, asenapine did not affect the activities of CYP2C9 and CYP2C19. The results obtained in the two in vitro experimental models are coherent, which strengthen the conclusions drawn from this study. The potent inhibition of CYP1A2 by asenapine displays $K_{i}$ value which is situated in the range of the $K_{i}$ values observed for such potent CYP1A2 inhibitors as furafylline and fluvoxamine $\left(K_{i}=0.12-3 \mu \mathrm{M}\right.$, depending on a substrate), as well as in the range of the therapeutic concentrations of the neuroleptic tested [3, 4, 8, 9, 16]. Similarly, the $K_{i}$ value for CYP2D6 inhibition by asenapine is close to the $K_{i}$ values observed for such well-known inhibitors as tricyclic antidepressants or selective serotonin reuptake inhibitors, SSRIs [25]. The $\mathrm{IC}_{50}$ values obtained in our experiment confirm the ability of asenapine to strongly inhibit the activity of CYP1A2 and CYP2D6. 


\section{A Liver microsomes}

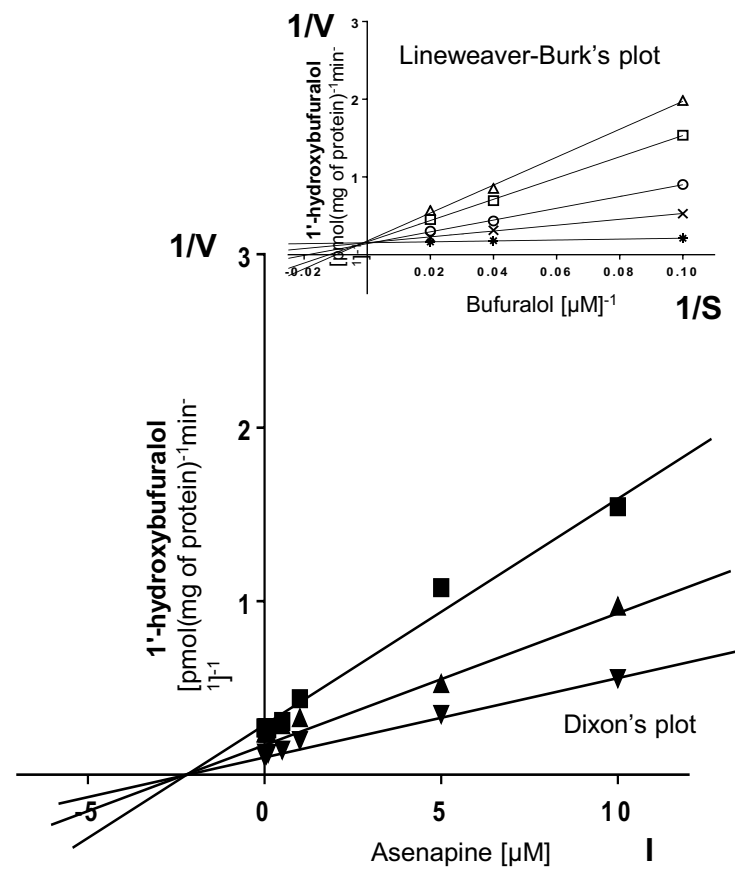

Fig. 2 The influence of asenapine on the activity of CYP2D6 measured as a rate of bufuralol 1'-hydroxylation. a Human liver microsomes $\left(K_{m}=5.1 \mu \mathrm{M}, V_{\max }=5.59 \mathrm{pmol} / \mathrm{mg}\right.$ protein $\left./ \mathrm{min}\right)$. B Human cDNA-expressed CYP2D6 (Supersomes CYP2D6) $\left(K_{m}=6.6 \mu \mathrm{M}\right.$, $V_{\max }=4.1 \mathrm{pmol} / \mathrm{pmol} \mathrm{CYP} / \mathrm{min}$ ). Each point represents the mean value of two independent analyses. $V$ velocity of the reaction, $I$ the

Although the therapeutic plasma concentrations of asenapine reach up to $0.1 \mu \mathrm{M}[9,26]$, its concentration in the liver may be several times higher than in the plasma owing to its physicochemical properties $(\log P=4.9$ for the neutral and 1.4 for cationic form; $\mathrm{pK}_{\mathrm{a}}=9.64$ for amine and 8.6 for the protonated base) and related tissue distribution pattern $[27,28]$. Basic lipophilic drugs are characterized by extensive accumulation in tissues due to nonspecific binding to cellular membranes and uptake by acidic subcellular compartments such as lysosomes [29-31]. These properties were shown in animal experiments for antidepressant drugs and phenothiazine neuroleptics in vitro [31-36] and in vivo [37, 38]. Moreover, it was observed in clinical studies that the concentration of thioridazine and its metabolites in the liver was 3- to 20-fold higher than that in the blood [39], while the concentration of haloperidol in the liver was 900 -fold higher than that in plasma [40]. Hence, a potent inhibition of CYP1A2 and CYP2D6 by asenapine observed in vitro in the present study may be expected in vivo, since the $\mathrm{K}_{\mathrm{i}}$ values

\section{B Supersomes 2D6}

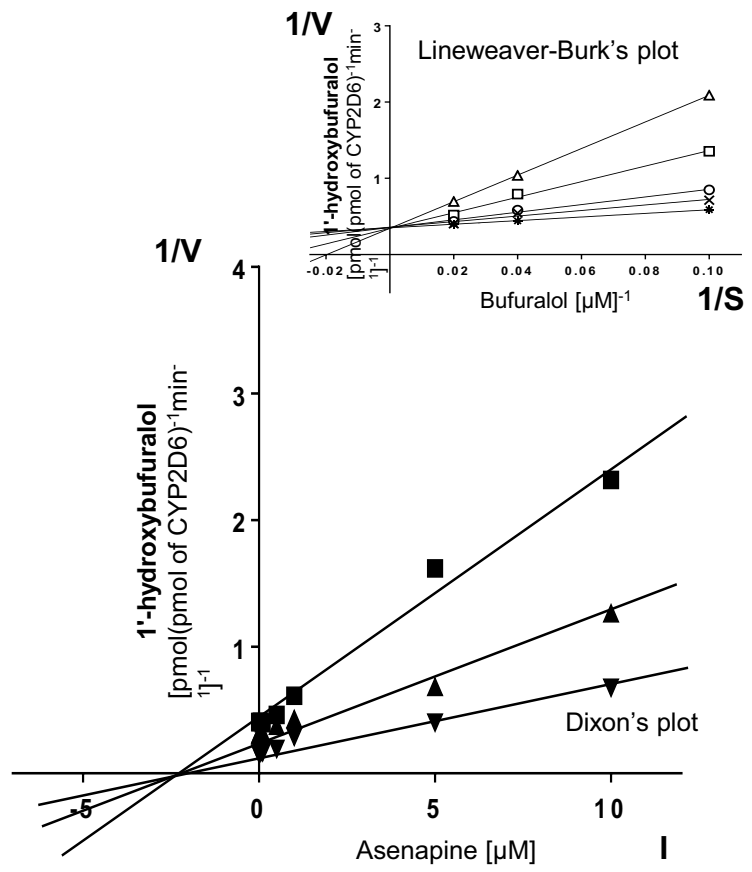

concentration of the inhibitor (asenapine), $S$ the concentration of the substrate (bufuralol). The $K_{i}$ values and mechanisms of inhibition are shown in Table 1. Dixon's plots (the main plots): the bufuralol concentration of $10 \mu \mathrm{M}(\mathbf{\square}), 25 \mu \mathrm{M}(\mathbf{\Delta})$, and $50 \mu \mathrm{M}(\boldsymbol{\nabla})$. LineweaverBurk's plots (inserts): control—no asenapine $(\boldsymbol{*})$; the asenapine concentration of $0.5 \mu \mathrm{M}(\mathbf{x}), 1 \mu \mathrm{M}(\bigcirc), 5 \mu \mathrm{M}(\square)$, and $10 \mu \mathrm{M}(\triangle)$

calculated for human liver microsomes (3.2 and $1.75 \mu \mathrm{M}$, respectively) are close to the presumed concentration range for asenapine in the liver of psychiatric patients. In line with these findings, it was shown that asenapine doubled the concentration of paroxetine (a CYP2D6 substrate) in the blood plasma of psychiatric patients [12]. Since asenapine is both a substrate and an inhibitor of CYP1A2 and CYP2D6, it seems possible that this neuroleptic can also inhibit its own metabolism.

On the other hand, the inhibition of CYP3A4 by asenapine demonstrated in vitro in the present study seems to be of limited significance in vivo, since the calculated $K_{i}$ values $(27-31 \mu \mathrm{M})$ are above the presumed concentration range of asenapine in human liver during pharmacotherapy and the $\mathrm{IC}_{50}$ values are much higher than those obtained for CYP1A2 or CYP2D6.

The knowledge of the ability of asenapine to inhibit CYP1A2 and CYP2D6 is of pharmacological and clinical importance, since this drug is administered to patients for 


\section{A Liver microsomes}

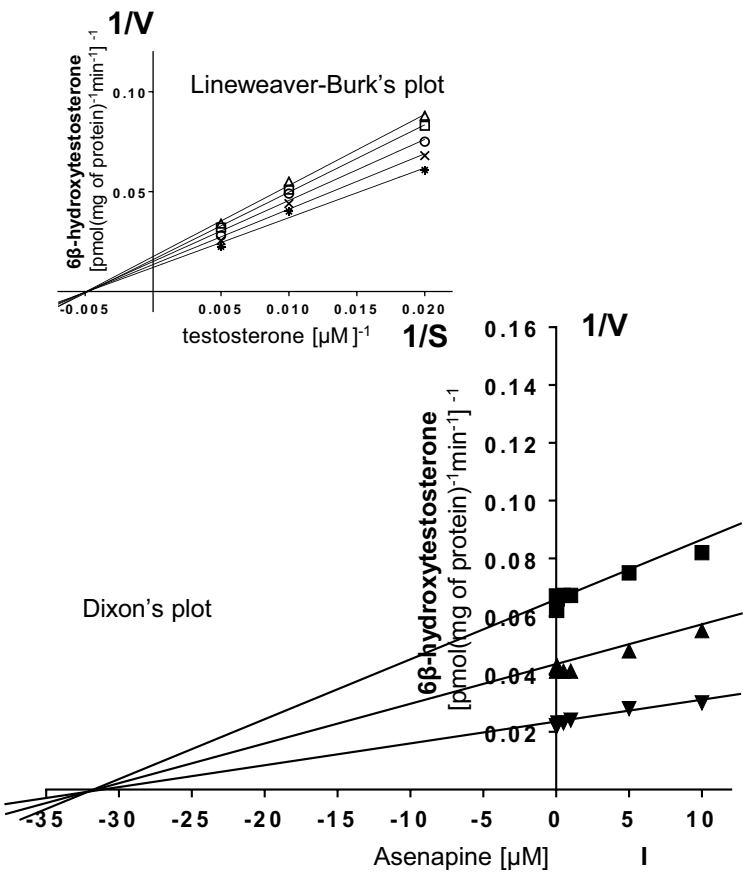

Fig. 3 The influence of asenapine on the activity of CYP3A4 measured as a rate of testosterone $6 \beta$-hydroxylation. a Human liver microsomes $\left(K_{m}=283 \mu \mathrm{M}, V_{\max }=72.9 \mathrm{pmol} / \mathrm{mg}\right.$ protein $\left./ \mathrm{min}\right)$. b Human cDNA-expressed CYP3A4 (Supersomes CYP3A4) $\left(K_{m}=428 \mu \mathrm{M}\right.$, $\left.V_{\max }=42.9 \mathrm{pmol} / \mathrm{pmol} \mathrm{CYP} / \mathrm{min}\right)$. Each point represents the mean value of two independent analyses. $V$ velocity of the reaction, $I$ the concentration of the inhibitor (asenapine), $S$ the concentration of

\section{B Supersomes 3A4}

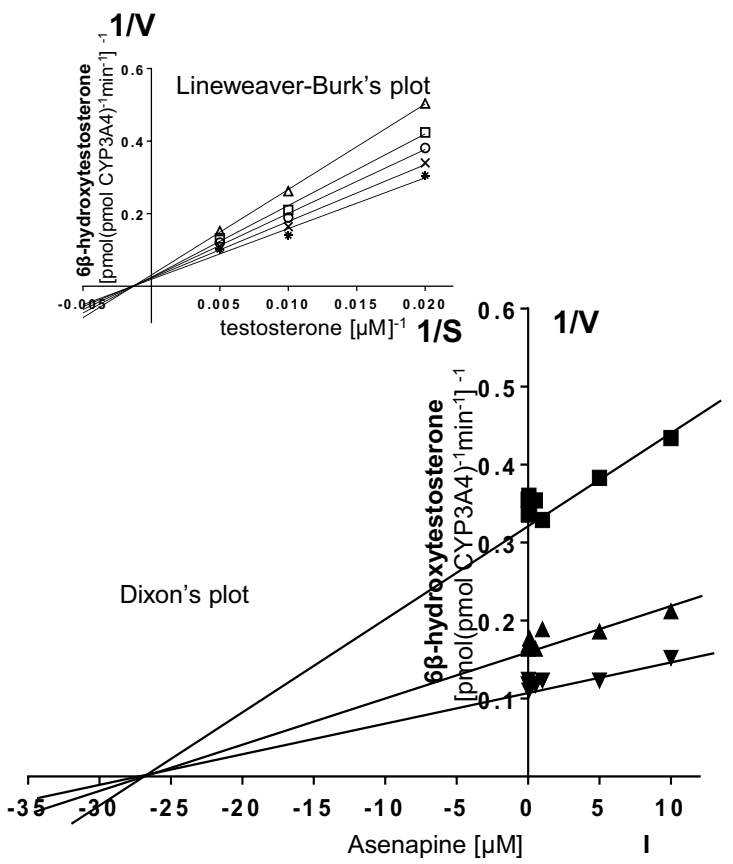

the substrate (testosterone). The $K_{i}$ values and mechanisms of inhibition are shown in Table 1. Dixon's plots (the main plots): the testosterone concentration of $50 \mu \mathrm{M}(\boldsymbol{\square}), 100 \mu \mathrm{M}(\boldsymbol{\Delta})$, and $200 \mu \mathrm{M}$ $(\boldsymbol{\nabla})$. Lineweaver-Burk's plots (inserts): control-no asenapine (*); the asenapine concentration of $0.5 \mu \mathrm{M}(\mathbf{x}), 1 \mu \mathrm{M}(\bigcirc), 5 \mu \mathrm{M}(\square)$, and $10 \mu \mathrm{M}(\triangle)$

Table 1 The ability of asenapine to inhibit CYP1A2, CYP2D6 and CYP3A4 activities in vitro in human liver microsomes and human cDNAexpressed CYP enzymes (Supersomes)

\begin{tabular}{|c|c|c|c|c|c|c|}
\hline \multirow[t]{2}{*}{ Inhibitor } & \multicolumn{6}{|c|}{ Inhibition of CYP-specific reactions by asenapine $K_{i}(\mu \mathrm{M})$ and type of inhibition } \\
\hline & \multicolumn{2}{|c|}{ Caffeine 3- $N$-demethylation (CYP1A2) } & \multicolumn{2}{|c|}{ Bufuralol 1'-hydroxylation (CYP2D6) } & \multicolumn{2}{|c|}{ Testosterone $6 \beta$-hydroxylation (CYP3A4) } \\
\hline \multirow[t]{2}{*}{ Asenapine } & Liver microsomes & $\begin{array}{l}\text { Supersomes } \\
\text { CYP1A2 }\end{array}$ & Liver microsomes & $\begin{array}{l}\text { Supersomes } \\
\text { CYP2D6 }\end{array}$ & Liver microsomes & Supersomes CYP3A4 \\
\hline & 3.2 (mixed) & 3.2 (mixed) & 1.75 (competitive) & 1.89 (competitive) & $\begin{array}{l}31.3 \text { (non-compet- } \\
\text { itive) }\end{array}$ & $\begin{array}{l}27.3 \text { (non-compet- } \\
\text { itive) }\end{array}$ \\
\hline
\end{tabular}

The presented inhibition constants $\left(K_{i}\right)$ for the inhibition of particular CYP-specific reactions by asenapine were obtained using a non-linear regression analysis (Program Sigma Plot 12.3; Enzyme Kinetics) and are shown graphically in Figs. 1a, b; 2a, b and 3a, b (Dixon's plots). The mechanisms of inhibition were estimated on the basis of changes in the $K_{m}$ and/or $V_{\max }$ values of the tested inhibitor (asenapine) and are shown graphically in the inserts of Figs. 1a, b; 2a, b and 3a, b (Lineweaver-Burk's plots)

months or years, and very often in combination with other clinically important drugs that are substrates of the abovementioned CYP enzymes. Therefore, the inhibition of those CYPs by asenapine may produce drug-drug interactions. The obtained results suggest that pharmacokinetic interactions involving asenapine and substrates of CYP2D6 (e.g., tricyclic antidepressants, SSRIs, codeine, dextromethorphan, debrisoquine, metoprolol, and propranolol) or CYP1A2 (e.g., caffeine, theophylline, phenacetin, tricyclic antidepressants, and propranolol) are likely to occur in patients during co-administration of the above-mentioned drugs. It is also worth stressing that caffeine, which was used in 
Table 2 The $\mathrm{IC}_{50}$ values obtained for the asenapine inhibition of cytochrome P450 enzyme activities in vitro in human liver microsomes and human cDNA-expressed CYP enzymes (Supersomes)

\begin{tabular}{|c|c|c|c|}
\hline \multirow[t]{2}{*}{ Enzyme } & \multirow[t]{2}{*}{ Marker reaction } & \multicolumn{2}{|c|}{ Asenapine $-\mathrm{IC}_{50}(\mu \mathrm{M})$} \\
\hline & & Liver microsomes & Supersomes \\
\hline CYP1A2 & Caffeine 3 - $N$-demethylation & 0.697 & 0.751 \\
\hline CYP2C9 & Diclofenac 4'-hydroxylation & $\begin{array}{l}\text { No inhibition } \\
>1000\end{array}$ & $\begin{array}{l}\text { No inhibition } \\
>1000\end{array}$ \\
\hline CYP2C19 & Perazine $N$-demethylation & $\begin{array}{l}\text { No inhibition } \\
>1000\end{array}$ & $\begin{array}{l}\text { No inhibition } \\
>1000\end{array}$ \\
\hline CYP2D6 & Bufuralol 1'-hydroxylation & 0.391 & 0.398 \\
\hline CYP3A4 & Testosterone $6 \beta$-hydroxylation & 6.123 & 8.682 \\
\hline
\end{tabular}

The $\mathrm{IC}_{50}$ values were estimated for the following substrate concentrations: caffeine $400 \mu \mathrm{M}$, diclofenac $10 \mu \mathrm{M}$, perazine $100 \mu \mathrm{M}$, bufuralol $50 \mu \mathrm{M}$, and testosterone $100 \mu \mathrm{M}$

\section{Liver microsomes}

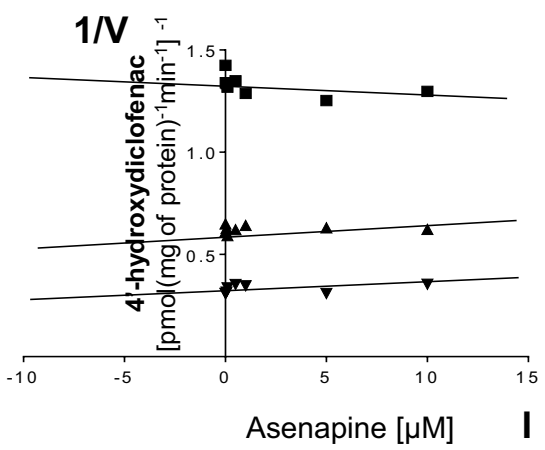

Liver microsomes

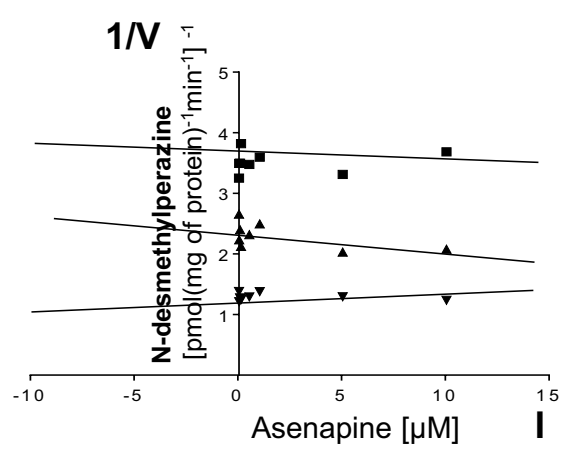

\section{A CYP2C9}

Supersomes

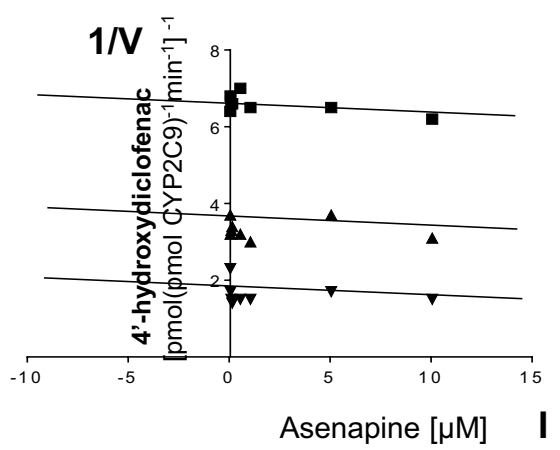

\section{B CYP2C19}

\section{Supersomes}

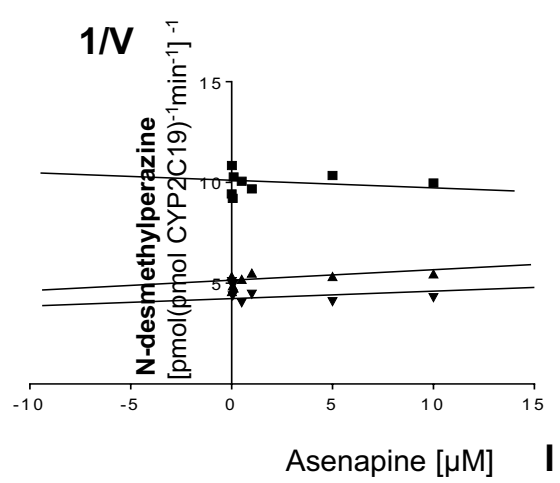

Fig. 4 The influence of asenapine on the activity of CYP2C9 (a) measured as a rate of diclofenac 4'-hydroxylation and CYP2C19 (b) measured as a rate of perazine $N$-demethylation. The enzyme activity was estimated in human liver microsomes $\left(K_{m}=136.8 \mu \mathrm{M}\right.$, $V_{\max }=21.02 \mathrm{nmol} / \mathrm{mg}$ protein $/ \mathrm{min}$ for diclofenac 4'-hydroxylation; $K_{m}=199.9 \mu \mathrm{M} ; V_{\max }=1.58 \mathrm{nmol} / \mathrm{mg}$ protein $/ \mathrm{min}$ for perazine $\mathrm{N}$-demethylation) and Supersomes CYP2C9 and CYP2C19 $\left(K_{m}=131.9 \mu \mathrm{M}, V_{\max }=213.6 \mathrm{pmol} / \mathrm{pmol} \mathrm{CYP} / \mathrm{min}\right.$ for diclofenac 4'-hydroxylation; $K_{m}=162.3 \mu \mathrm{M}, V_{\max }=39.4 \mathrm{pmol} / \mathrm{pmol} \mathrm{CYP} / \mathrm{min}$ for perazine $N$-demethylation). Each point represents the mean value of two independent analyses. $V$ velocity of the reaction, $I$ the concentration of the inhibitor (asenapine), $S$ the concentration of the substrate (diclofenac or perazine). Dixon's plots: a the diclofenac concentration of $5 \mu \mathrm{M}(\mathbf{\square}), 10 \mu \mathrm{M}(\mathbf{\Delta})$, and $25 \mu \mathrm{M}(\boldsymbol{\nabla})$; b the perazine concentration of $50 \mu \mathrm{M}(\boldsymbol{\square}), 100 \mu \mathrm{M}(\boldsymbol{\Delta})$, and $200 \mu \mathrm{M}(\boldsymbol{\nabla})$ 
our experiment as a CYP1A2 marker substance, is also a component of numerous drugs and beverages, like coffee, tea, and energy drinks. Its therapeutic concentrations of $10-100 \mu \mathrm{M}$ may be reached during high coffee consumption [41]. Considering a very broad spectrum of caffeine action on neuronal transmission [42] and the presented ability of asenapine to inhibit CYP1A2, a special caution should be taken when the two substances are administered jointly.

The obtained results may also have physiological and toxicological significance, since CYP1A2 and CYP2D6 are implicated in the biotransformation of endogenous substances, such as estradiol (CYP1A2) or neurosteroids (CYP2D6) and environmental contaminants polycyclic aromatic hydrocarbons (CYP1A2) [5, 43].

Acknowledgements The study was supported by Grant Opus 6 no. 2013/11/B/NZ7/01627 from the National Science Centre, Kraków, Poland, and by statutory funds from the Maj Institute of Pharmacology, PAS, Kraków, Poland.

\section{Compliance with ethical standards}

Conflict of interest The authors declare that there is no conflict of interest.

Open Access This article is licensed under a Creative Commons Attribution 4.0 International License, which permits use, sharing, adaptation, distribution and reproduction in any medium or format, as long as you give appropriate credit to the original author(s) and the source, provide a link to the Creative Commons licence, and indicate if changes were made. The images or other third party material in this article are included in the article's Creative Commons licence, unless indicated otherwise in a credit line to the material. If material is not included in the article's Creative Commons licence and your intended use is not permitted by statutory regulation or exceeds the permitted use, you will need to obtain permission directly from the copyright holder. To view a copy of this licence, visit http://creativecommons.org/licenses/by/4.0/.

\section{References}

1. Shimada T, Yamazaki H, Mimura M, Inui Y, Guengerich FP. Interindividual variations in human liver cytochrome P-450 enzymes involved in the oxidation of drugs, carcinogens and toxic chemicals: studies with liver microsomes of 30 Japanese and 30 Caucasians. J Pharmacol Exp Ther. 1994;270:414-23.

2. Lin JH. CYP induction-mediated drug interactions: in vitro assessment and clinical implications. Pharm Res. 2006;23:1089-116.

3. Rostami-Hodjegan A, Tucker GT. Simulation and prediction of in vivo drug metabolism in human populations from in vitro data. Nat Rev Drug Discov. 2007;6:140-8.

4. Pelkonen O, Turpeinen M, Hakkola J, Honkakoski P, Hukkanen $\mathrm{J}$, Raunio H. Inhibition and induction of human cytochrome P450 enzymes: current status. Arch Toxicol. 2008;82:667-715.

5. Zanger UM, Schwab M. Cytochrome P450 enzymes in drug metabolism: regulation of gene expression, enzyme activities, and impact of genetic variation. Pharmacol Ther. 2013;138:103-41.

6. Prior TI, Baker GB. Interactions between the cytochrome P450 system and the second-generation antipsychotics. J Psychiatry Neurosci. 2003;28:99-112.
7. Citrome L. Asenapine review, part I: chemistry, receptor affinity profile, pharmacokinetics and metabolism. Expert Opin Drug Metab Toxicol. 2014;10:893-903.

8. Stoner SC, Pace HA. Asenapine: a clinical review of a secondgeneration antipsychotic. Clin Ther. 2012;34:1023-40.

9. Citrome L. A review of the pharmacology, efficacy and tolerability of recently approved and upcoming oral antipsychotics: an evidence-based medicine approach. CNS Drugs. 2013;27:879-911.

10. Meltzer HY, Li Z, Kaneda Y, Ichikawa J. Serotonin receptors: their key role in drugs to treat schizophrenia. Prog Neuropsychopharmacol Biol Psychiatry. 2003;27:1159-72.

11. van de Wetering-Krebbers SFM, Jacobs PL, Kemperman GJ, Spaans E, Peeters PAM, Delbressine LPC, et al. Metabolism and excretion of asenapine in healthy male subjects. Drug Metab Dispos. 2011;39:580-90.

12. Mandrioli R, Protti M, Mercolini L. Novel atypical antipsychotics: metabolism and therapeutic drug monitoring (TDM). Curr Drug Metab. 2015;16:141-51.

13. Cascorbi I. Drug interactions-principles, examples and clinical consequences. Dtsch Arztebl Int. 2012;109:546-55 (quiz 556).

14. Ring BJ, Binkley SN, Vandenbranden M, Wrighton SA. In vitro interaction of the antipsychotic agent olanzapine with human cytochromes P450 CYP2C9, CYP2C19, CYP2D6 and CYP3A. Br J Clin Pharmacol. 1996;41:181-6.

15. Shin JG, Soukhova N, Flockhart DA. Effect of antipsychotic drugs on human liver cytochrome P-450 (CYP) isoforms in vitro: preferential inhibition of CYP2D6. Drug Metab Dispos. 1999;27:1078-84.

16. Prakash C, Kamel A, Cui D, Whalen RD, Miceli JJ, Tweedie D. Identification of the major human liver cytochrome $\mathrm{P} 450$ isoform(s) responsible for the formation of the primary metabolites of ziprasidone and prediction of possible drug interactions. Br J Clin Pharmacol. 2000;49(Suppl 1):35S-42S.

17. Wójcikowski J, Daniel WA. Perazine at therapeutic drug concentrations inhibits human cytochrome P450 isoenzyme 1A2 (CYP1A2) and caffeine metabolism - an in vitro study. Pharmacol Rep. 2009;61:851-8.

18. Gervasini G, Caballero MJ, Carrillo JA, Benitez J. Comparative cytochrome p450 in vitro inhibition by atypical antipsychotic drugs. ISRN Pharmacol. 2013;2013:792456.

19. Basińska-Ziobroń A, Daniel WA, Wójcikowski J. Inhibition of human cytochrome P450 isoenzymes by a phenothiazine neuroleptic levomepromazine: an in vitro study. Pharmacol Reports. 2015;67:1178-82.

20. Daniel WA, Kot M, Wójcikowski J. Influence of classic and atypical neuroleptics on caffeine oxidation in rat liver microsomes. Pol J Pharmacol. 2003;55:1055-61.

21. Schmitz G, Lepper H, Estler C-J. High-performance liquid chromatographic method for the routine determination of diclofenac and its hydroxy and methoxy metabolites from in vitro systems. $\mathrm{J}$ Chromatogr B Biomed Sci Appl. 1993;620:158-63.

22. Wójcikowski J, Pichard-Garcia L, Maurel P, Daniel WA. The metabolism of the piperazine-type phenothiazine neuroleptic perazine by the human cytochrome P-450 isoenzymes. Eur Neuropsychopharmacol. 2004;14:199-208.

23. Hiroi $T$, Chow $T$, Imaoka $S$, Funae Y. Catalytic specificity of CYP2D isoforms in rat and human. Drug Metab Dispos. 2002;30:970-6.

24. Wójcikowski J, Haduch A, Daniel WA. Effect of classic and atypical neuroleptics on cytochrome P450 3A (CYP3A) in rat liver. Pharmacol Rep. 2012;64:1411-8.

25. Daniel WA. The influence of long-term treatment with psychotropic drugs on cytochrome P450: the involvement of different mechanisms. Expert Opin Drug Metab Toxicol. 2005;1:203-17.

26. Hiemke C, Bergemann N, Clement HW, Conca A, Deckert J, Domschke K, et al. Consensus guidelines for therapeutic drug 
monitoring in neuropsychopharmacology: update 2017. Pharmacopsychiatry. 2018;51:9-62.

27. PubChem. Asenapine n.d. https://pubchem.ncbi.nlm.nih.gov/ compound/3036780. Accessed 13 Nov 2019.

28. Drug Approval Package: Saphris NDA 22117 n.d. https://www. accessdata.fda.gov/drugsatfda_docs/nda/2009/022117s000TOC. cfm. Accessed 13 Nov 2019.

29. Francesco CD, Bickel MH. Membrane lipids as intracellular binders of chlorpromazine and related drugs. Chem Biol Interact. 1977; 16:335-46.

30. MacIntyre AC, Cutler DJ. The potential role of lysosomes in tissue distribution of weak bases. Biopharm Drug Dispos. 1988;9:513-26.

31. Daniel WA. Mechanisms of cellular distribution of psychotropic drugs. Significance for drug action and interactions. Prog Neuropsychopharmacol Biol Psychiatry. 2003;27:65-73.

32. Daniel WA, Wójcikowski J. Contribution of lysosomal trapping to the total tissue uptake of psychotropic drugs. Pharmacol Toxicol. 1997;80:62-8.

33. Daniel WA, Wójcikowski J. Interactions between promazine and antidepressants at the level of cellular distribution. Pharmacol Toxicol. 1997;81:259-64.

34. Daniel WA, Wójcikowski J. Lysosomal trapping as an important mechanism involved in the cellular distribution of perazine and in pharmacokinetic interaction with antidepressants. Eur Neuropsychopharmacol. 1999;9:483-91.

35. Daniel WA, Wójcikowski J. The role of lysosomes in the cellular distribution of thioridazine and potential drug interactions. Toxicol Appl Pharmacol. 1999;158:115-24.
36. Daniel WA, Wójcikowski J, Pałucha A. Intracellular distribution of psychotropic drugs in the grey and white matter of the brain: the role of lysosomal trapping. Br J Pharmacol. 2001;134:807-14.

37. Wójcikowski J, Daniel WA. Distribution interactions between perazine and antidepressant drugs In vivo studies. Pol J Pharmacol. 2000;52:449-57.

38. Wójcikowski J, Daniel WA. Thioridazine-fluoxetine interaction at the level of the distribution process in vivo. Pol J Pharmacol. 2002;54:647-54.

39. Dinovo EC, Bost RO, Sunshine I, Gottschalk LA. Distribution of thioridazine and its metabolites in human tissues and fluids obtained postmortem. Clin Chem. 1978;24:1828-30.

40. Forsman A, Larsson M, Lundborg H, Renstrom P. On the distribution and elimination of haloperidol in cholecystectomized patients. Eur J Drug Metab Pharmacokinet. 1981;6:249-53.

41. Kot M, Daniel WA. Caffeine as a marker substrate for testing cytochrome P450 activity in human and rat. Pharmacol Rep. 2008;60:789-97.

42. Fisone G, Borgkvist A, Usiello A. Caffeine as a psychomotor stimulant: mechanism of action. Cell Mol Life Sci. 2004;61:857-72.

43. Haduch A, Daniel WA. The engagement of brain cytochrome P450 in the metabolism of endogenous neuroactive substrates: a possible role in mental disorders. Drug Metab Rev. 2018;50:415-29.

Publisher's Note Springer Nature remains neutral with regard to jurisdictional claims in published maps and institutional affiliations. 